\title{
Relationship between Caretakers Variable on Age and Coping Strategies of Caretakers Attending To Patients with Cancer Problems
}

\author{
M. Sandhya Rani $^{1 *}$, Dr. Nasreenbanu ${ }^{2}$
}

\section{ABSTRACT}

The present study makes an attempt to understand the Relationship between Caretakers Variable on Age and Coping Strategies of Caretakers Attending to Patients with Cancer Problems. Caretakers who were ready and willing to extend their cooperation for in depth interview were selected as population for the study. Thus a total number of 80 caretakers were selected purposively for conducting the present study.

Keywords: Age, Caretakers, Coping Strategies, Cancer Problems

Becoming a parent, is one of the most powerful of the human experiences, is often accompanied with feelings of celebration and relief, but it can also be a time of anxiety, and stress. The term "Parenting" is derived from the Latin root pario, meaning life-giver, and encompasses much more than just the care giving activities parents perform.

Bjork and Wiebe (2005) found that Parents describe their experience immediately following the child's cancer diagnosis as particularly distressing, characterized by fear, sadness, grief, loneliness, and dependence on others. Using psychological evaluation tools and self-report instruments, the study team measured traumatic stress, depression and anxiety among the mothers.

Last JM et al. (2001) found that, Quality of Life (QOL) is an estimate of remaining life free of impairment, disability or handicap. Chronic conditions put increased stress on the child and the child's parents and siblings. Children with any chronic condition have twice the risk of

\footnotetext{
${ }^{1}$ Department Of Human Development And Family Studies, College Of Home science, Professor Jayashankar Telangana State Agricultural University, Hyderabad India

${ }^{2}$ Major Advisor, Principal Scientist,AICRP- Human Development, PG \& RC, Professor Jayashankar Telangana State Agricultural University, Hyderabad India

*Responding Author
}

Received: February 3, 2017; Revision Received: February 12, 2017; Accepted: February 15, 2017

(C) 2017 Rani S, Nasreenbanu; licensee IJIP. This is an Open Access Research distributed under the terms of the Creative Commons Attribution License (www.creativecommons.org/licenses/by/2.0), which permits unrestricted use, distribution, and reproduction in any Medium, provided the original work is properly cited. 


\section{Relationship between Caretakers Variable on Age and Coping Strategies of Caretakers Attending To Patients with Cancer Problems}

developing mental health disorders of healthy children, and three times the risk if they have an accompanying disability.

Vogels T et al. (1998) revealed that, the parents rate their children's Quality of Life to be worse than the children themselves do It may be affected by their expectations for the child and by the fact they have different definitions and understanding of a disease and its consequences for the future.

\section{RESEARCH METHOD}

A total number of 80 caretakers who were ready and willing to extend their cooperation for in depth interview were selected as population for the present study. The sample was limited to caretakers for two reasons. First much of the research on family care giving which has been done in aboard only this area of study is almost non- existent in the state of Telangana. Secondly, reports have suggested that parents are particularly vulnerable to the strains of illness experienced due to multiple roles to be shouldered. The main focus of the study was to provide various alternative strategies for the caretakers.

\section{RESEARCH FINDINGS AND DISCUSSION}

\section{Research Findings and Discussion}

Caretakers who were ready and willing to extend their cooperation for in depth study were selected as population for the study that is "Relationship between Caretakers Variable on Age and Coping Strategies of Caretakers Attending to Patients with Cancer Problems". Thus a total 80 caretakers were selected purposively for conducting the present study.

\section{Description of the Cancer Problems}

1. Cancer illness is the most acute pressure, which any family may experience and it also creates a potential threat equally to both the victim and the caretaker.

2. For the patient, the threat involves painful medical procedures, surgeries, and its side effects, and frequent hospitalization.

Relationship between Caretakers Variable on Age and Coping Strategies

\begin{tabular}{|c|c|c|c|}
\hline \multirow{2}{*}{$\begin{array}{l}\text { Approach coping } \\
\text { Caretaker Variable: Age }\end{array}$} & & \multicolumn{2}{|l|}{ Avoidance coping } \\
\hline & & & \\
\hline Logical Analysis & $0.92 * *$ & Cognitive Avoidance & $0.64 * *$ \\
\hline Positive Appraisal & $0.95 * *$ & Acceptance & $0.59 * *$ \\
\hline Guidance and Support & $0.92 * *$ & Alternative Rewards & $0.68 * *$ \\
\hline Problem Solving & $0.92 * *$ & Emotional Discharge & $-0.82 * *$ \\
\hline
\end{tabular}

$\mathrm{P} * 0.05$; level of significance; $\mathrm{P} * * 0.01$, level of significance, $\mathrm{r}$ tab value at $5 \%$ level of significance $=0.2500 ; \mathrm{r}$ tab value at $1 \%$ level of significance is 0.3248 .

(c) The International Journal of Indian Psychology, ISSN 2348-5396 (e) | ISSN: 2349-3429 (p) | 193 


\section{Relationship between Caretakers Variable on Age and Coping Strategies of Caretakers Attending To Patients with Cancer Problems}

The above table presents the relationship between caretaker variable on age and coping strategies of caretakers attending to children with cancer problems. Out of the eight coping responses, the first four represents Approach coping and the remaining four comes under Avoidance coping.

Under Approach coping, the first area is logical analysis, which deals with handling the situation objectively, finding some personal meaning to the situation and anticipating the new demands. In this area, the level of significance is $0.92 * *$ logical analysis in coping with the situation.

The second area under Approach coping is Positive appraisal, which includes caretaker's ability to see the good side of the situation and how the event could change one's life in a positive way. In this area, the level of significance is $0.95^{* *}$ positive appraisals in coping with the situation.

The third area under Approach coping is guidance and support, which involves seeking support from relations, talking to a closed person about the problem and praying for guidance and strength. In this area, the level of significance is $0.92 * *$ caretakers sought guidance and support.

The fourth area under Approach coping is problem solving, which involves a plan of action, using alternate ways of solving problem and trying out new ways of confronting the problem. In this area, the level of significance is $0.92^{* *}$ used to problem solving strategies.

Under Avoidance coping, the first area is cognitive avoidance i.e. avoiding the situation, denial, day dreaming, and imagining that problems would go away on their own. In this area, level of significance is $0.64 * *$ used cognitive avoidance.

The second area under avoidance coping is acceptance i.e., accepting the situation with all its intensity, realizing that one has no control over the problem and believing that outcome would be decided by fate. In this area, the level of significance is $0.59 * *$.

The third area under avoidance coping is seeking alternate rewards i.e., getting involved in new activities, making new friends and indulging in more recreational activities. In this area, the level of significance is $0.68^{* *}$

The fourth area under avoidance coping is emotional discharge, which involves yelling or shouting to let off steam, showing the frustration of role capacity on others and keeping away from people in general. In this area, the level of significance is $-0.82^{* *}$ used avoidance coping emotional discharge technique. 


\section{Relationship between Caretakers Variable on Age and Coping Strategies of Caretakers Attending To Patients with Cancer Problems}

\section{CONCLUSION}

The data collected with respect to relationship between caretaker variable on age and coping strategies of caretakers attending to patients with cancer problems revealed that caretakers used both approach and avoidance coping styles. It indicated that age has significant positive relationship with all dimensions of approach coping strategies. Further it can be noted that age has no significant relationship with cognitive avoidance and alternative rewards of avoidance coping strategies but significant positive relationship with resigned acceptance and significant negative relationship with emotional discharge.

\section{Acknowledgments}

The author appreciates all those who participated in the study and helped to facilitate the research process.

Conflict of Interests: The author declared no conflict of interests.

\section{REFERENCES}

Bjork, M., Wiebe, T and Hallstrom, I. 2005. Striving to Survive: Families Lived Experiences When a Child is Diagnosed with Cancer. Journal of Pediatric Oncology Nursing. 22(5): 265- 275.

Last J M, Spasoff RA, Harris SS, Thuriaux MC, Anderson JB. (2001) Quality of Life Research. A dictionary of Epidemiology. 4th edition. New York: Oxford University Press. 148, 12: 655.

Vogels T, Verrips GH, Verloove-Vanhorick SP, Fekkes M, Kamphuis RP, Koopman HM, Theunissen NC, Wit JM. 1998. Measuring health-related quality of life in children: the development of the TACQOL parent form. Qual Life Res.7 (5): 457-465.

How to cite this article: Rani S, Nasreenbanu (2017), Relationship between Caretakers Variable on Age and Coping Strategies of Caretakers Attending To Patients with Cancer Problems, International Journal of Indian Psychology, Volume 4, Issue 2, No. 89, ISSN:2348-5396 (e), ISSN:2349-3429 (p), DIP:18.01.099/20170402, ISBN:978-1-365-74162-3 